\title{
INVESTIGATION OF FINE PARTICULATE POLLUTION IN A COASTAL CITY WITH A MOBILE MONITORING PLATFORM
}

\author{
HOI K.I. \\ MOK K.M. * \\ YUEN K.V. \\ PUN M.H.
}

\author{
Department of Civil and Environmental Engineering \\ University of Macau, Av. Padre Tomás Pereira Taipa, \\ Macau SAR, China
}

Received: 08/04/13

Accepted: $13 / 05 / 13$ *to whom all correspondence should be addressed: e-mail: KMMOK@umac.mo

\begin{abstract}
Spatial and temporal variation of fine particulate pollution in a complex small coastal city, Macau, was investigated by using a mobile air quality monitoring platform. Real-time street level measurements of aerosol size distribution were carried out three times per day by using an on-board wide-range particle spectrometer along a designed route covering the main area of the city for one week. The measured distributions were then transformed into $\mathrm{PM}_{2.5}$ mass concentrations for assessment based on an empirical relation estimated from a co-located measurement calibration process. Within this week, the averaged $\mathrm{PM}_{2.5}$ mass concentrations of the morning, afternoon, and evening sessions are $51.76 \mu \mathrm{g} \mathrm{m}^{-3}, 28.87 \mu \mathrm{g} \mathrm{m}^{-3}$ and $30.77 \mu \mathrm{g} \mathrm{m}^{-3}$, respectively. By comparing the spatial statistics of the estimated $\mathrm{PM}_{2.5}$ concentrations with the US 24-hour primary NAAQS as a reference, a significant probability of exceedance (> 86\%) was observed in $1 / 3$ of the monitoring sessions, particularly in the mornings of high traffic volume. Meanwhile, majority of the hotspots were found in the districts of the Macau peninsula. In addition, by performing analysis of the backward trajectories, daily MODIS images, and comparison of the $\mathrm{PM}_{2.5}$ patterns of the entire route of three selected measuring sessions during weekdays and weekend, it was observed that long range transport of fine particulates may affect Macau in a larger scale. Therefore, regional land source influence could shadow the local one when the ambient conditions are met.
\end{abstract}

KEYWORDS: Macau, Mobile monitoring platform, $\mathrm{PM}_{2.5}$, Wide-range Particle Spectrometer.

\section{INTRODUCTION}

Particulate pollution arising from urbanization is a severe air pollution problem in most megacities and this problem is worth concerning due to its adverse impacts to people and the urban environment (Kan et al., 2007; Kim et al., 2006; Jacobson and Kaufman, 2006). Therefore, taking actions towards its proper management is necessary and urgent. The process requires many steps. Understanding the current condition of the city is obviously an initial but important one. Usual method of achieving this goal is by reviewing the data collected from the stations of a monitoring network which perform mass concentration measurements of $\mathrm{PM}_{2.5}$. However, these stations are normally sparsely distributed. The data recorded at each station can only reveal the situation of its nearby vicinity. This makes it difficult to perform detailed spatial assessment of the particulate pollution for the entire city. Thence, the objective of this study is to conduct an assessment within the Macau Special Administrative Region (SAR), a gaming mecca in the Pearl River Delta (PRD) region of China as a case study by using a mobile monitoring platform (Yao et al., 2005; Yao et al., 2007; Hu et al., 2012; Pirjola et al., 2012). Macau is on the western bank of the PRD. It has an area of 29.9 $\mathrm{km}^{2}$, comprised of the Macau Peninsula $9.3 \mathrm{~km}^{2}$, the islands of Taipa $\left(7.4 \mathrm{~km}^{2}\right)$ and Coloane $(7.6$ $\left.\mathrm{km}^{2}\right)$ and the reclaimed area COTAI $\left(5.6 \mathrm{~km}^{2}\right)$. Three bridges connect Macau to Taipa. In previous aerosol studies of Macau, Mok and Hoi (2005) found that the seasonal behaviour of $\mathrm{PM}_{10}$ is related 
to the Asian monsoons and tropical cyclones can cause $\mathrm{PM}_{10}$ episodes during summer. Hoi et al. $(2008,2009,2010)$ further found through modelling that the daily averaged $\mathrm{PM}_{10}$ concentrations in Macau can be varied by its past history, the change of the replenishing air masses, and the rainfall. However, overall assessment of the particulate pollution within this city has not been addressed yet. Therefore, the present study is a timely and important one to fill this gap.

\section{SAMPLING INSTRUMENTS AND METHODOLOGY}

The Mobile Air Quality Monitoring Platform (MAP) (Yao et al., 2005) leased from the Hong Kong University of Science and Technology was employed to carry out street level measurements of particle size distribution function using a Wide-range Particle Spectrometer (WPS) to cover the main area of Macau in seven consecutive days (Feb.18 to 24, 2009). The WPS used can measure the size-segregated particle number concentrations from $0.01 \mu \mathrm{m}$ to $10 \mu \mathrm{m}$ by combining laser light scattering, electrical mobility and condensation particle counting technologies (Liu et al., 2010). It is used on MAP instead of a Tapered Element Oscillating Microbalance (TEOM) since the vibration of external sources especially from the moving platform could interfere with the TEOM's operation (Cantrell et al., 1996).

Within these seven consecutive days, three times of continuous street level measurements per day (local time: 08:00 AM-10:00 AM, 16:00 PM-18:00 PM, 21:00 PM-23:00 PM) were carried out with MAP along a designed route (length: $45 \mathrm{~km}$ ) that covers the main areas of Macau as shown in figure 1. Given the small size of Macau, travelling along this route requires about one hour and twenty two minutes on average at an average speed of $32.5 \mathrm{~km} \mathrm{hr}^{-1}$. With the sampling interval for the WPS set at 38 seconds, each WPS reading covers about 343 meters of road length on average; i.e. about $1 / 131$ of the total route length. Therefore, this study is the first of its kind that could give a snapshot of the fine particulate pollution for the entire city within a short period of time for systematic comparison. Besides assessing the pollution condition of the whole route, the route is also divided into eight segments (M1 to M8) according to the official district classification of the Macau SAR Government, so that district based assessment could be performed later.

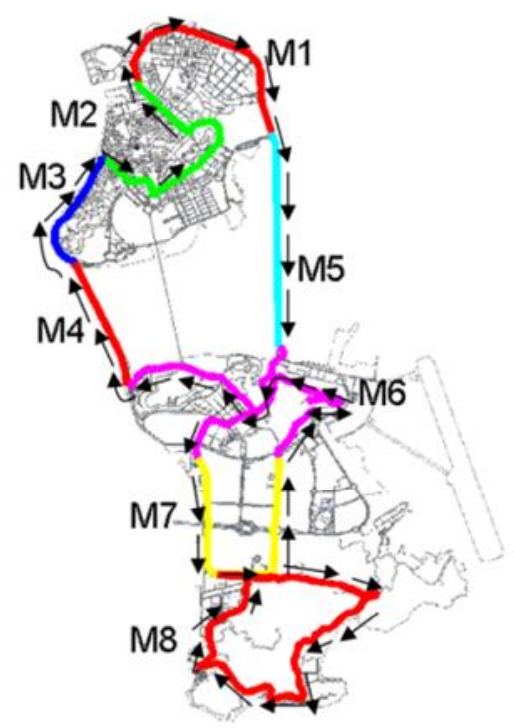

Figure 1. Route and its district classification travelled by MAP

Although using MAP is a good approach for assessing the particulate pollution over the city of Macau within a short period, the aerosol size distributions obtained by the on-board WPS cannot be compared directly with known references for assessment. Since the target values set by the international air quality standards for fine particulate pollution assessment are based on the total mass concentrations of $\mathrm{PM}_{2.5}$, transforming the measured aerosol size distribution function into $\mathrm{PM}_{2.5}$ mass concentrations for analysis is necessary. This is done with an empirical relationship derived from the co-located measurements of the WPS on MAP and the TEOM at a fixed ambient (Taipa) air quality monitoring station during each overnight period (local time: 11:30 PM - 07:30 AM tomorrow) of the seven studied days. This fixed ambient station is located at the top of the Taipa Grande Hill with an altitude of $159.3 \mathrm{~m}$. It is believed that the aerosol spectrum sampled at this 
location is representative of the general ambient condition of the city. Meanwhile, the overnight sampling period is between the evening and the following morning street-level-measurement periods. The record may capture the diurnal variability of the relative humidity as well as the different chemical composition in $\mathrm{PM}_{2.5}$ (background value vs. local emissions). Furthermore, the overnight measurements were made daily. The results can also reflect the daily variability of the two mentioned factors due to different replenishing air masses caused by the variation of synoptic scale weather system within the studied period. Procedures of the transformation are explained in the following section.

\section{TRANSFORMATION OF WPS MEASUREMENTS}

The WPS can divide the entire size range from $0.01 \mu \mathrm{m}$ to $10 \mu \mathrm{m}$ into 67 diameter segments and measure the corresponding particle number concentrations. The discretized aerosol size distribution function $n_{i}$ is given by:

$n_{i} \equiv n(i \Delta \log D)=\frac{N_{i}}{\Delta \log D}, i=1, \ldots, 67\left(\mathrm{~cm}^{-3}\right)$

where $D$ and $N_{i}$ denote the particle diameter and the total particle number concentration of the $i^{\text {th }}$ logarithmic diameter segment $\left[\log D_{i-1}, \log D_{i}\right]$, respectively. To perform the transformation, it is necessary to estimate the empirical relation between the volume concentrations $V_{t, P M 2.5}$ deduced from the WPS measurements and the measured $\mathrm{PM}_{2.5}$ mass concentrations [ $P M_{2.5}$. By assuming that all particles are spherical, the total particle volume concentration of the $i^{\text {th }}$ diameter segment is given by:

$$
V_{i} \equiv \frac{\pi}{6} D_{m, i}^{3} N_{i}=\frac{\pi}{6} D_{m, i}^{3} n_{i} \Delta \log D, i=1, \ldots, 67\left(\mu \mathrm{m}^{3} \mathrm{~cm}^{-3}\right)
$$

where $D_{m, i}$ denotes the $i^{\text {th }}$ mean particle diameter given by $\left(D_{i-1}+D_{i}\right) / 2$. Among the 67 segments, segments from 1 to 58 refer to the fine fraction of the respirable particulates $\left(\mathrm{PM}_{2.5}\right)$ and the rest represents the coarse fraction $\left(\mathrm{PM}_{2.5-10}\right)$. The total volume concentration of $\mathrm{PM}_{2.5}$ is obtained by summing up the volume concentrations of the first 58 segments:

$V_{t, P M 2.5}=\sum_{i=1}^{58} V_{i}\left(\mu \mathrm{m}^{3} \mathrm{~cm}^{-3}\right)$

The ordinary least squares (OLS) linear regression between the measured $\mathrm{PM}_{2.5}$ mass concentrations by TEOM and the derived volume concentrations from WPS yields the following equation:

$\left[P M_{2.5}\right]=1.12 V_{t, P M 2.5}+1.75$

The slope of $1.12 \mathrm{~g} \mathrm{cc}^{-1}$ represents the apparent density of $\mathrm{PM}_{2.5}$ with the assumption that the density is constant in all diameter segments associated with $\mathrm{PM}_{2.5}$. The estimated apparent density is comparable to the range of $1.05 \mathrm{~g} \mathrm{cc}^{-1}$ to $2.36 \mathrm{~g} \mathrm{cc}^{-1}$ found from the study of the urban $\mathrm{PM}_{2.5}$ at Augsburg, Germany (Pitz et al., 2008). The regression line has an $r^{2}$ value of 0.78 and a root-meansquare error (RMSE) of $9.08 \mu \mathrm{g} \mathrm{m}^{-3}$. The uncertainty of the regression may be due to the measurement errors of both instruments, and the significant hygroscopic growth of aerosols during days of high relative humidity $(>80 \%$ ) (Eichler et al., 2008) as well as the diurnal or daily variation in the chemical composition of $\mathrm{PM}_{2.5}$. Since the OLS regression assumes that the modelling error follows a Gaussian distribution with zero mean and its variance is the $R M S E^{2}$ according to the central limit theorem, error of the subsequent transformation of the route measurements by Eqn. (4) is assumed to follow the same distribution and variance. This will help to quantify the uncertainty associated with Eqn. (4) in the following discussion.

\section{RESULTS}

\section{District-based assessment}

To evaluate the severity of the fine particulate pollution of Macau within the seven consecutive days, the rational approach is to compare the estimated $\mathrm{PM}_{2.5}$ mass concentrations from the WPS measurements along the route with a target value adopted from a well-known air quality standard. Since there is currently no standard target value of $\mathrm{PM}_{2.5}$ designated for real-time or hourly measurements, the value of $35 \mathrm{\mu g} \mathrm{m}^{-3}$ which is the 24-hour primary National Ambient Air Quality Standards (NAAQS) set by the Environmental Protection Agency of the United States (USEPA) for $\mathrm{PM}_{2.5}$ is adopted. It is noted that the value chosen here is used mainly for reference, but not for the 
actual decision of the standard attainment as the duration of average used for analysing the measurements is no more than two hours even all data of the entire route in each run are considered.

Spatial statistics of the entire route and its eight segments (M1-M8) are studied first to assess the overall condition of the city as well as its district based distribution within the studied period. Table 1 shows their spatial averages of the estimated $\mathrm{PM}_{2.5}$ mass concentrations in the morning $(\mathrm{Mm})$ session, the afternoon (Ma) session and the evening (Me) session during Feb. 18 and 24, 2009. Hot spot and clean zone among the eight segments for a given session are identified by the maximum (orange) and the minimum (green) of the segment averages. For the spatial statistics of the entire route, exceedance of the target value $35 \mathrm{\mu g} \mathrm{m}^{-3}$ highlighted in red is observed in about one third of the monitoring sessions. To confirm these exceedances are not due to the statistical uncertainty of transforming the measured aerosol size distribution function into $\mathrm{PM}_{2.5}$ mass concentrations by Eqn. (4), the probability of exceedance $(P E)$ defined as the probability that the estimated concentration by Eqn. (4) is higher than $35 \mu \mathrm{g} \mathrm{m}^{-3}$ (the target value) is calculated and shown in Table 1. It was found that all monitoring sessions with exceedance have their PEs higher than $86 \%$. This means that the observed exceedances are very likely to happen. Hence, the fine particulate pollution of Macau was severe during the studied period. Within the sessions of exceedance, $57.1 \%$ occurred in the morning. It is believed that this is mainly caused by the morning traffic during the rush hour (08:00AM09:30AM).

For the district based spatial averages, the $\mathrm{PM}_{2.5}$ mass concentration exhibits high spatial variability among districts. Major hotspots are in the Macau peninsula at M1, M2 and M3 taking up about $85.7 \%$ of the maximum values among the monitoring sessions. As the Macau peninsula is the older part of the city with a higher population compared to the other two recently developed islands, it has a higher traffic volume, severer traffic congestion, narrower old streets surrounded by dense array of buildings, and more traffic lights that introduce frequent stop-and-go driving patterns. These factors are expected to induce more traffic emissions and adverse dispersion conditions in the Macau peninsula leading to severer pollution condition. On the contrary, most of the clean zones $(\sim 90.7 \%$ of the monitoring sessions) are in the bridges connecting the Macau peninsula and the Taipa island (M4 and M5), the main roads connecting the Taipa island and the Coloane island (M7), and the Coloane island (M8). This is due to the much lower traffic volumes in M7 and M8 as well as the better dispersion conditions exhibit in all of these districts.

Although the local traffic emission is a plausible leading cause for the observed high $\mathrm{PM}_{2.5}$ concentrations, its daily emission pattern should not vary significantly within these seven days; hence this factor alone is not sufficient to explain the observed larger fluctuations of $\mathrm{PM}_{2.5}$ mass concentrations between the measurement sessions shown in Table 1. Therefore, another important factor to be considered is the ambient wind condition as it controls the dispersion condition as well as the type of the replenishing air masses being brought to Macau within the studied period. To examine this effect, a whole area assessment is performed next.

\section{Whole area assessment}

In order to investigate the influence of the wind condition on the fine particulate pollution of Macau, assessment of the instantaneous $\mathrm{PM}_{2.5}$ mass concentrations along the route is performed for three selected cases during weekdays (Feb. 19 and 20) and weekend (Feb. 22), respectively. The wind conditions in Macau are reviewed first. Figure 2 shows the hourly wind velocity vectors recorded at the ambient (Taipa) station over the studied period. It is noted that Macau was prevailed by southeasterly and southerly winds except for Feb. 20. On Feb. 20, there was the passage of a cold front moving south from the mainland to the PRD, which led to the transition of wind directions from southerly in the night-time of Feb. 19 to northerly in the early morning of Feb. 20. Checking the route averaged $\mathrm{PM}_{2.5}$ concentration of this period in Table 1, the value increases significantly from 25.82 $\mu \mathrm{g} \mathrm{m}^{-3}$ (evening session, Feb. 19) to $74.82 \mu \mathrm{g} \mathrm{m}^{-3}$ (morning session, Feb. 20). To investigate the underlying mechanism, four-day backward trajectories associated with these two periods are generated by the Hybrid Single Particle Lagrangian Integrated Trajectory Model (HYSPLIT) of the NOAA Air Resources Laboratory (Draxler and Rolph, 2013; Rolph, 2013) to check the possible types of air masses brought to Macau. 
Table 1. Spatial averages of the estimated $\mathrm{PM}_{2.5}$ mass concentrations $\left(\mu \mathrm{g} \mathrm{m}^{-3}\right)$ of the entire route and its eight segments during Feb. 18 and 24, 2009; ( $S$ = session of measurement; $R$ = route segment where average is taken)

\begin{tabular}{|c|c|c|c|c|c|c|c|c|c|c|c|c|}
\hline Date & \multicolumn{3}{|c|}{$18 / 2$ Wed } & \multicolumn{3}{|c|}{ 19/2 Thurs } & \multicolumn{3}{|c|}{ 20/2 Fri } & \multicolumn{3}{|c|}{$21 / 2$ Sat } \\
\hline$R>$ & $\mathrm{Mm}$ & $\mathrm{Ma}$ & $\mathrm{Me}$ & $\mathrm{Mm}$ & $\mathrm{Ma}$ & $\mathrm{Me}$ & $\mathrm{Mm}$ & Ma & $\mathrm{Me}$ & $\mathrm{Mm}$ & $\mathrm{Ma}$ & $\mathrm{Me}$ \\
\hline Entire & 34.40 & 18.71 & 21.48 & 22.68 & 15.49 & 25.82 & 74.82 & 34.93 & 28.99 & 30.76 & 47.11 & 45.15 \\
\hline $\mathrm{PE}$ & 47.37 & 3.64 & 6.82 & 8.74 & 1.58 & 15.60 & 100 & 49.69 & 25.40 & 32.03 & 90.88 & 86.82 \\
\hline M1 & 34.38 & 22.84 & 15.22 & 16.77 & 26.23 & 24.33 & 63.02 & 34.88 & 28.73 & 28.06 & 44.42 & 47.87 \\
\hline M2 & 48.13 & 22.01 & 32.16 & 26.69 & 16.88 & 44.94 & 96.93 & 38.24 & 34.14 & 31.46 & 53.00 & 59.07 \\
\hline M3 & 65.22 & 14.89 & 31.18 & 58.62 & 14.38 & 46.79 & & 35.18 & 31.90 & 42.82 & 57.01 & 56.49 \\
\hline M4 & 31.24 & 15.22 & 21.31 & 18.72 & 38.47 & 28.47 & & 34.65 & 28.49 & 33.29 & 34.45 & 33.14 \\
\hline M5 & 34.22 & 18.88 & 13.28 & 13.76 & 15.74 & 19.38 & 71.64 & 34.97 & 27.40 & 22.94 & 39.47 & 38.21 \\
\hline M6 & 27.27 & 17.15 & 21.49 & 22.80 & 13.43 & 22.23 & 65.83 & 33.94 & 29.37 & 29.81 & 41.82 & 36.00 \\
\hline M7 & 25.58 & 17.52 & 15.86 & 12.73 & 11.05 & 13.27 & 70.99 & 32.44 & 25.04 & 30.44 & 42.48 & 42.23 \\
\hline M8 & 26.47 & 15.83 & 14.80 & 11.73 & 10.00 & 11.47 & 69.07 & 31.42 & 24.56 & 30.43 & 52.19 & 38.54 \\
\hline Date & \multicolumn{3}{|c|}{$22 / 2$ Sun } & \multicolumn{3}{|c|}{ 23/2 Mon } & \multicolumn{3}{|c|}{ 24/2 Tue } & & & \\
\hline$R$ & Mm & Ma & Me & $\mathrm{Mm}$ & Ma & Me & $\mathrm{Mm}$ & Ma & $\mathrm{Me}$ & & & \\
\hline Entire & 65.31 & 27.15 & 48.00 & 74.89 & 26.09 & 18.44 & 59.48 & 32.58 & 27.48 & & & \\
\hline $\mathrm{PE}$ & 99.96 & 19.36 & 92.39 & 100 & 16.32 & 3.41 & 99.65 & 39.49 & 20.38 & & & \\
\hline M1 & 71.64 & 40.92 & 51.53 & 78.34 & 48.23 & 26.77 & 66.34 & 34.33 & 25.81 & & & \\
\hline M2 & 62.36 & 43.10 & 52.86 & 82.62 & 44.73 & 26.99 & 74.03 & 35.65 & 30.58 & & & \\
\hline M3 & 81.66 & 26.16 & 55.31 & 132.34 & 18.81 & 17.80 & 97.81 & 33.13 & 27.70 & & & \\
\hline M4 & 52.86 & 16.21 & 44.78 & 103.18 & 12.68 & 12.37 & 44.71 & 36.69 & 25.08 & & & \\
\hline M5 & 59.15 & 34.08 & 44.63 & 62.44 & 23.80 & 15.36 & 77.27 & 26.32 & 24.21 & & & \\
\hline M6 & 63.42 & 23.30 & 46.67 & 69.90 & 18.43 & 18.29 & 48.34 & 31.68 & 24.24 & & & \\
\hline M7 & 70.07 & 21.46 & 45.06 & 51.52 & 9.96 & 12.52 & 23.20 & 34.33 & 38.54 & & & \\
\hline M8 & 64.04 & 15.48 & 44.43 & 51.79 & 17.36 & 12.63 & 45.44 & 27.64 & 21.76 & & & \\
\hline
\end{tabular}

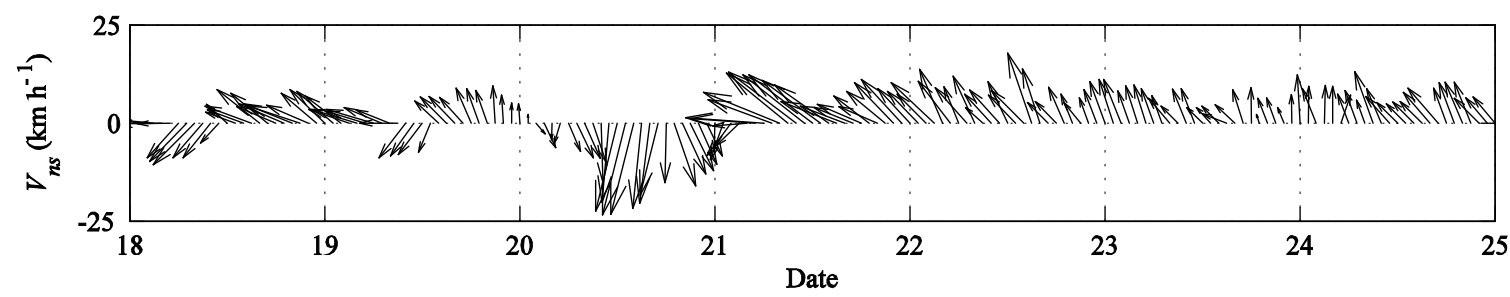

Figure 2. Hourly wind velocity recorded at the ambient (Taipa) station during Feb. 18 and 24, 2009; $V_{n s}$ is the north-south component of the wind velocity vector ( $\downarrow$ Northerly wind, $\uparrow$ Southerly wind, $\leftarrow$ Easterly wind, $\rightarrow$ Westerly wind)

Figure 3a shows two four-day backward trajectories arriving Macau with UTC starting time of 13:00 (local time: 21:00) on Feb. 19. The two trajectories are with starting height of $500 \mathrm{~m}$ (line color: red) and $1000 \mathrm{~m}$ (line color: blue), respectively. According to the nearby vertical profile of the potential temperature recorded at the King's Park of Hong Kong (about $60 \mathrm{~km}$ from the Taipa station in Macau) as well as the time histories of the normalized backscattering signal of LIDAR at Yuen Long and Sha Tau Kok of Hong Kong, the boundary layer thickness at UTC 12:00 (local time 20:00) on Feb. 19 was between $400 \mathrm{~m}$ and $500 \mathrm{~m}$. Therefore, the lower level trajectory $(500 \mathrm{~m})$ serves to reveal the transport of the boundary layer, while the upper one $(1000 \mathrm{~m})$ represents the movement of the residual layer. Results show that the $1000 \mathrm{~m}$ trajectory originated at the west end of the northern Pacific Ocean. Hence, clean and humid air masses could be transported to Macau at the upper level. On the other hand, the $500 \mathrm{~m}$ trajectory originated from Northern China. It passed through Korea, 


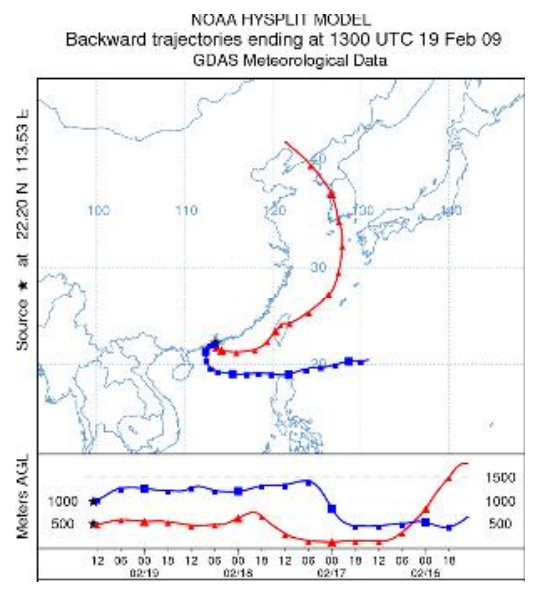

(a)

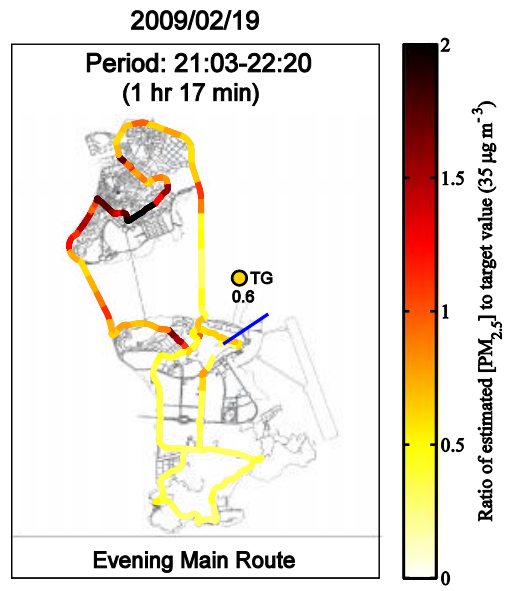

(b)

Figure 3. (a) Four-day backward trajectories arriving Macau at 13:00 UTC (local time: 21:00) Feb.19, 2009, (b) Spatial plot of the ratios of estimated $\mathrm{PM}_{2.5}$ mass concentrations to the target value of NAAQS in the evening session of Feb.19, 2009

the East China Sea, Taiwan and entered the South China Sea before it was bent towards Macau by the south-easterly and southerly winds. When the air masses passed southern Taiwan at 00:00 UTC (local time: 08:00) on Feb. 18, the $\mathrm{PM}_{2.5}$ mass concentration recorded at the Sinying station of YunChia-Nan there was $16 \mu \mathrm{g} \mathrm{m}^{-3}$. It implies that the $\mathrm{PM}_{2.5}$ concentration in the replenishing air masses before reaching Macau should be low. Figure $3 b$ shows the spatial plot of the ratio of estimated $\mathrm{PM}_{2.5}$ concentration to the target value $\left(35 \mu \mathrm{g} \mathrm{m}^{-3}\right)$ for the evening session of Feb. 19. The ratio at the ambient Taipa station (TG) is also shown in the figure for reference. Since there are some outliers of abnormally high $\mathrm{PM}_{2.5}$ mass concentrations recorded in the route, they would distort the contrast of the spatial distribution if plotted to scale. An upper limit of 2 is set for the color bar. Any ratio that is larger than 2 is plotted with the same color as the upper limit. Initial observation is that the ambient Taipa station and its vicinity have consistent colors, meaning that the estimated $\mathrm{PM}_{2.5}$ mass concentrations from the WPS measurements are close to those recorded by TEOM. This further validates the performance of the empirical relation estimated by Eqn. (4). Examining the color distribution of the route in Figure $3 b$, clear differences between districts are seen. The hot spots (M2 and M3) are at the center of the Macau peninsula up north, while the clean districts are at the COTAI reclaimed area (M7) and the rural Coloane Island (M8) down south. Because the replenishing air masses brought to Macau then were relatively clean as indicated by the backward trajectories shown in Figure $3 a$, these differences are believed due mainly to the distributions of the local traffics at the time; i.e. busy in the city center and quiet in the rural areas at night.

As for the sudden increase of the route averaged $\mathrm{PM}_{2.5}$ concentration in the morning session of Feb. 20 from the lower value in the evening session of Feb. 19 mentioned earlier, the four-day backward trajectories arriving Macau with starting time of 00:00 UTC (local time 08:00) on Feb. 20 and the spatial plot of the ratio of estimated $\mathrm{PM}_{2.5}$ concentration to the target value $\left(35 \mu \mathrm{g} \mathrm{m}^{-3}\right)$ for the morning session of Feb. 20 in Figure 4 provide some explanations.

The two four-day backward trajectories in Figure 4a use the same starting heights of $500 \mathrm{~m}$ (line color: red) and $1000 \mathrm{~m}$ (line color: blue) as those in Figure 3a due to similar boundary layer thickness. These two trajectories originated from similar locations with the $1000 \mathrm{~m}$ one at Korea and the $500 \mathrm{~m}$ one at the north end of the East China Sea. Their earlier passages were similar passing through the central part of the East China Sea and reaching the south-eastern coast of China and the South China Sea at 00:00 UTC 18 Feb 2009, respectively. Their last two day passages before reaching Macau were more complicated especially for the $500 \mathrm{~m}$ trajectory. The lower trajectory stayed close to the coastline of China. It was bent north to enter the inland of Guangdong province when it was near Macau but only to make a sharp southerly turn shortly after to reach Macau at 00:00 UTC (local time 08:00) 20 Feb 2009. Spatial plot of the ratio of estimated $\mathrm{PM}_{2.5}$ concentration to the target value for the morning session on Feb. 20 in Figure 4b shows exceedance of the target value over the entire route with weak spatial variability. (Note that the data of segments M3 and M4 


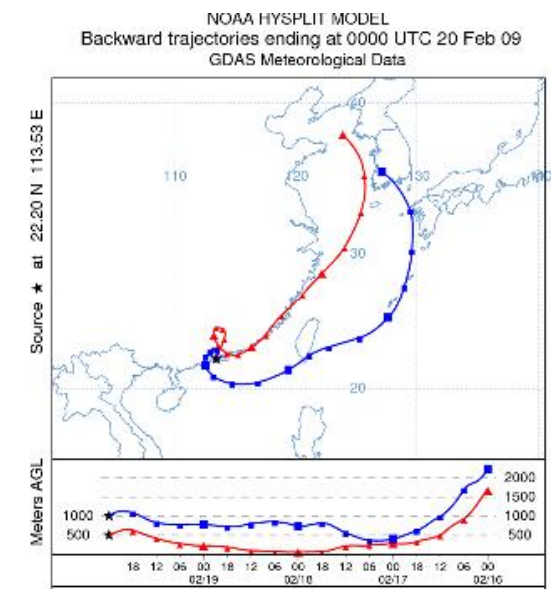

(a)

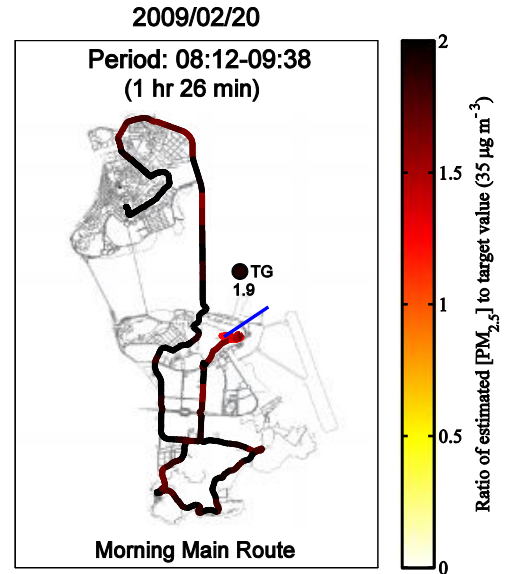

(b)

Figure 4. (a) Four-day backward trajectories arriving Macau at 00:00 UTC (local time: 08:00)

Feb. 20, 2009, (b) Spatial plot of the ratios of estimated $\mathrm{PM}_{2.5}$ mass concentrations to the target value of NAAQS in the morning session of Feb. 20, 2009

are missing due to malfunction of the equipment in that morning session.) Therefore, it is obvious that this rapid rise over the whole area of Macau could not be caused by local traffic emissions alone. It must be from the effect of a larger scale phenomenon. Examination of the complicated backward trajectories coupled with the aerosol patterns in the air masses of the region up to the time of the day and the day before is needed.

Using the Giovanni (Acker and Leptoukh, 2007) online data system developed and maintained by the NASA GES DISC, two daily MODIS images of the aerosol optical depth (AOD) at $550 \mathrm{~nm}$ in Asia from Terra between 00:00 UTC 18 Feb. 2009 and 00:00 UTC 20 Feb. 2009 were produced in Figure 5 . Figure 5a shows that the AODs of the region passed by both trajectories (Figure 4a) on Feb. 18 were low (<0.5), meaning that the $\mathrm{PM}_{2.5}$ mass concentrations in the replenishing air masses may still be low till 00:00 UTC (local time: 08:00) Feb. 19. Figure 5b shows that the south-eastern China including the PRD region was covered by an aerosol plume with the AOD near the upper scale of the color bar between 00:00 UTC 19 Feb. and 00:00 UTC 20 Feb. Referencing to the boomeranglike segment of the $500 \mathrm{~m}$ backward trajectory closing in to Macau in Figure 4a, the return path indicated that air masses originally left Macau moving north started to be brought back by the northerly wind due to the arrival of a cold front at the north end of the Guangdong province at 06:00 UTC 19 Feb. Therefore, the large aerosol plume shown in Figure $5 \mathrm{~b}$ would be brought to Macau leading to the up surge of the $\mathrm{PM}_{2.5}$ concentrations over the whole city that shadowed the effect of the local traffic emissions as shown in Figure $4 b$.

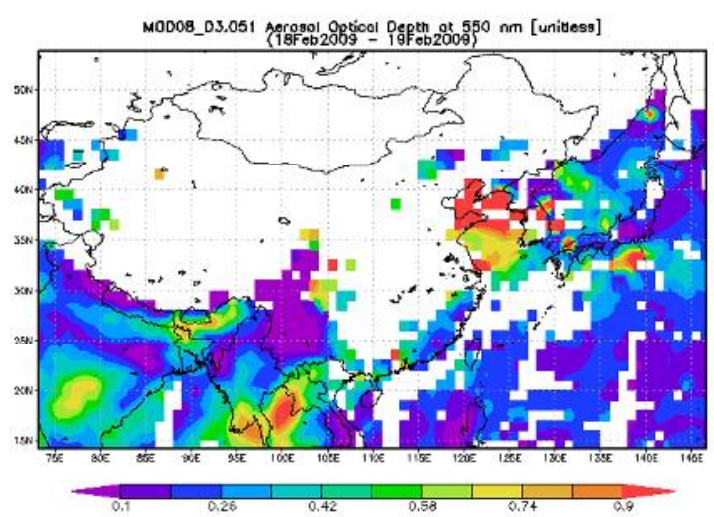

(a)

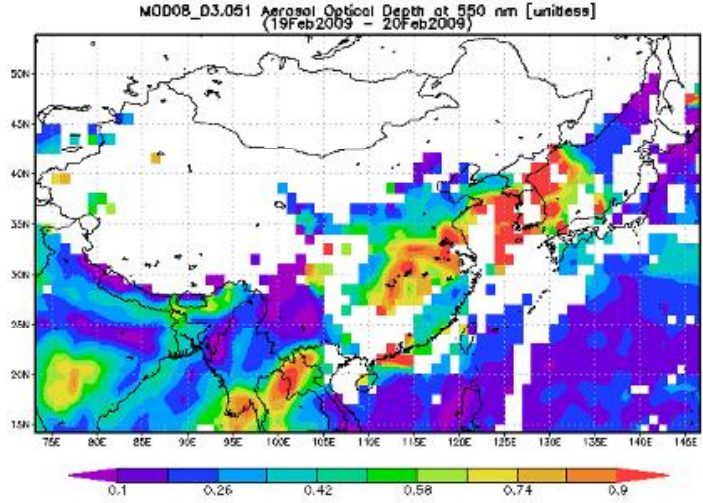

(b)

Figure 5. MODIS images of aerosol optical depth at $550 \mathrm{~nm}$ in Asia from Terra (a) 00:00 UTC (local time: 08:00) Feb. 18, 2009 - 00:00 UTC Feb. 19, 2009, (b) 00:00 UTC (local time: 08:00)

Feb. 19, 2009 - 00:00 UTC Feb. 20, 2009 
From Table 1, it is noted that four out of the six measurement sessions in the weekend of Feb. 21 and 22 have their route $\mathrm{PM}_{2.5}$ concentration averages exceeding the target value with the morning session of Feb. 22 being the highest. Prevailing wind condition during that period shown in Figure 2 indicates mainly south-easterly to southerly blowing from the sea. Therefore, it is interesting to investigate why the sea breeze could cause the observed high $\mathrm{PM}_{2.5}$ concentration. Figure 6a shows two four-day backward trajectories arriving Macau with UTC starting time of 00:00 (local time: 08:00) on Feb. 22. As the estimated mixing height was within 250 and $500 \mathrm{~m}$ then, the same starting heights as the two previous cases are adopted here. The $1000 \mathrm{~m}$ trajectory is found originated at the region of the South China Sea, west of the Philippines, where the observed AODs $(<0.26)$ on Feb. 18 was low (see Figure 5a). Therefore, clean and humid air masses may be transported to Macau at the upper level. On the other hand, the $500 \mathrm{~m}$ trajectory originated at the north end of the East China Sea and circulated around there for some time before moving south. The observed AODs (>0.9) of that area on Feb. 18 to Feb. 19 was high (See Figure 5a,b), so that the replenishing air masses coming from there in the boundary layer may be particle-enriched. As these polluted air masses headed south and reached the east side of Taiwan at 18:00 UTC Feb. 20, the AODs observed there were between 0.58 and 0.82 as shown in Figure 7 , indicating the presence of moderately polluted plumes. When these air masses continued to move south into the South China Sea and then turned north to reach Macau in the morning of Feb. 22, they may bring some of the particulates picked up along their journey to Macau.

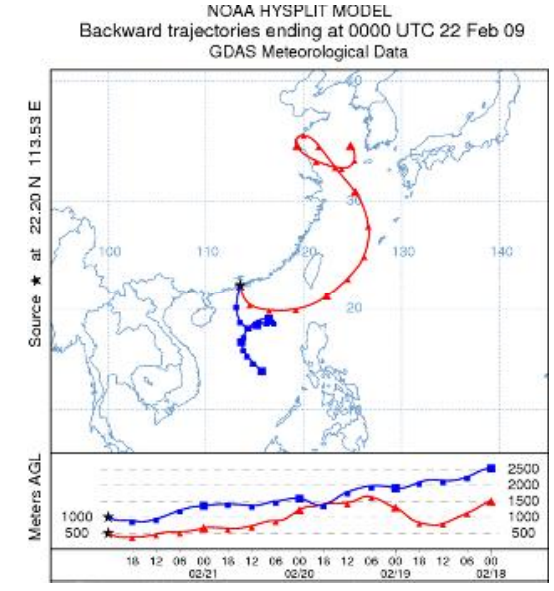

(a)

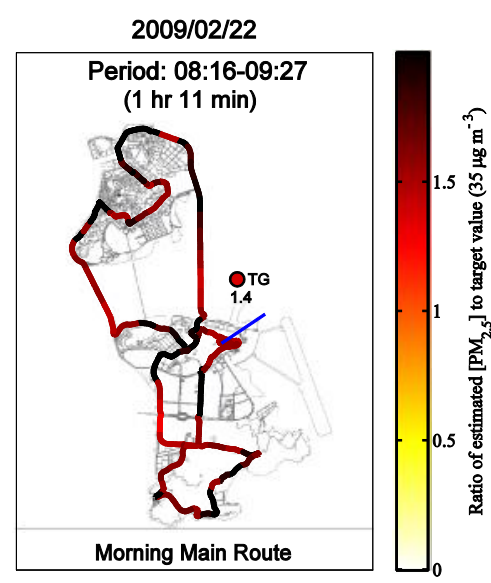

(b)

Figure 6. (a) Four-day backward trajectories arriving Macau at 00:00 UTC (local time: 08:00) Feb. 22, 2009, (b) Spatial plot of the ratios of estimated $\mathrm{PM}_{2.5}$ mass concentrations to the target value of NAAQS in the morning session of Feb. 22, 2009

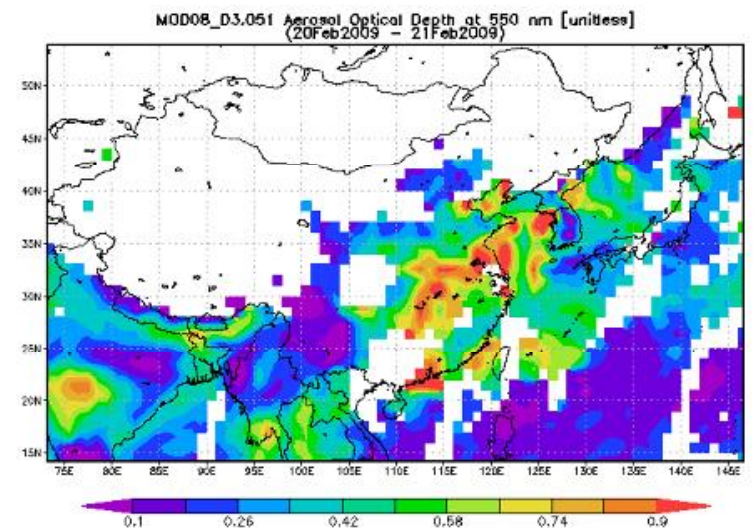

Figure 7. MODIS images of aerosol optical depth at $550 \mathrm{~nm}$ in Asia from Terra 00:00 UTC (local time: 08:00) Feb. 20, 2009 - 00:00 UTC Feb. 21, 2009 
If they did, the effect would be in larger scale. Figure $6 b$ shows the spatial plot of the ratio of estimated $\mathrm{PM}_{2.5}$ mass concentration to the target value in the morning session of Feb. 22. The $\mathrm{PM}_{2.5}$ concentrations along the whole route were high with some spatial variability. This confirms that the main contribution to the pollution should be from the regional sources rather than the local ones. In addition, the increase in the averaged $\mathrm{PM}_{2.5}$ mass concentration of the entire route from the evening session of Feb. 21 to the morning session of Feb. 22 shown in Table 1 is only $20.16 \mu \mathrm{g} \mathrm{m}^{-3}$. It suggests that the increase could be caused by the moderately polluted plumes that the air masses passed by the region near Taiwan earlier.

\section{CONCLUSIONS}

In this study, the Mobile Air Quality Monitoring Platform was used to perform assessment of the street-level fine particulate pollution along a route designed to cover the main area of Macau during Feb. 18 to 24 of 2009. Based on the district based assessment of the estimated $P_{2.5}$ mass concentrations within seven consecutive days, it was found that Macau had a significant probability of exceedance $(>86 \%$ ) of the target value (primary standard of NAAQS) within $1 / 3$ of the studied period; hence concluding the severity of fine particulate pollution. In addition, the spatial variability of the local traffic emissions and the dispersion conditions were concluded to be the plausible causes of the hot spots and clean zones of $\mathrm{PM}_{2.5}$ observed along the route. Based on the analysis of the backward trajectories, the daily MODIS images and the whole area assessment of the instantaneous $\mathrm{PM}_{2.5}$ mass concentrations, it was concluded that the long-range transport of aerosols from mainland may lead to the rapid rise in the background concentrations over the entire area which shadow the pollution from local sources.

\section{ACKNOWLEDGEMENTS}

This work is supported by the Science and Technology Development Fund of Macau SAR (025/2011/A) and the University of Macau (UL019/08-Y5/CEE/MKM01/FST). The Macau Environmental Protection Bureau (DSPA), the Macau Meteorological and Geophysical Bureau (SMG), and the Institute for the Environment (INEV) at the Hong Kong University of Science and Technology (HKUST) are thanked for their collaborative efforts during the monitoring activities. The Macau SMG is thanked for supplying the air quality and meteorological data of the ambient station. The authors gratefully acknowledge the NOAA Air Resources Laboratory (ARL) for the provision of the HYSPLIT transport and dispersion model and/or READY website (http://ready.arl.noaa.gov) used in this publication. The NASA GES DISC is acknowledged for providing the daily MODIS images produced with the Giovanni online data system.

\section{REFERENCES}

Acker, J.G. and Leptoukh, G. (2007) Online Analysis Enhances Use of NASA Earth Science Data, Eos. Trans. AGU., 88, 14-17.

Cantrell, B.K., Stein, S.W., Patashnick, H. and Hassel, D. (1996) Status of a tapered element oscillating microbalance-based continuous respirable coal mine dust monitor, App. Occup. Environ. Hyg., 11, 624-629.

Draxler, R.R. and Rolph, G.D. (2013) HYSPLIT (Hybrid Single-particle Lagrangian Integrated Trajectory) Model access via NOAA ARL READY Website. NOAA Air Resources Laboratory, Silver Spring, MD. (http://ready.arl.noaa.gov/HYSPLIT.php)

Eichler , H., Cheng, Y.F., Birmili, W., Nowak, A., Wiedensohler, A., Bruggemann, E., Gnauk, T., Herrmann, H., Althausen, D., Ansmann, A., Engelmann, R., Tesche, M., Wendisch, M., Zhang, Y.H., Hu, M., Liu, S. and Zeng, L.M. (2008) Hygroscopic properties and extinction of aerosol particles at ambient humidity in South-Eastern China., Atmos. Environ., 42, 6321-6334.

Hu, S.S., Paulson, S.E., Fruin, S., Kozawa, K., Mara, S. and Winer, A.M. (2012) Observation of elevated air pollutant concentrations in a residential neighborhood of Los Angeles California using a mobile platform, Atmos. Environ., 51, 311-319.

Hoi, K.I., Yuen, K.V. and Mok, K.M. (2008) Kalman filter based prediction system for wintertime $\mathrm{PM}_{10}$ concentrations in Macau, Global NEST J., 10, 140-150.

Hoi, K.I., Yuen, K.V. and Mok, K.M. (2009) Prediction of daily averaged $\mathrm{PM}_{10}$ concentrations by statistical time-varying model, Atmos. Environ., 43, 2579-2581.

Hoi, K.I., Yuen, K.V. and Mok, K.M. (2010) Optimizing the performance of Kalman filter based statistical time-varying air quality models, Global NEST J., 12, 27-39.

Jacobson, M.Z. and Kaufman, Y.J. (2006) Wind reduction by aerosol particles, Geophys. Res. Lett., 33, L24814, doi:10.1029/2006GL027838. 
Kan, H.D., London, S.J., Chen, G.H., Zhang, Y.H., Song, G.X., Zhao, N.Q., Jiang, L.L. and Chen, B.H. (2007) Differentiating the effects of fine and coarse particles on daily mortality in Shanghai, China., Environ. Int., 33, 376-384.

Kim, Y.J., Kim, K.W., Kim, S.D., Lee, B.K. and Han, J.S. (2006) Fine particulate matter characteristics and its impact on visibility impairment at two urban cities in Korea: Seoul and Incheon, Atmos. Environ., 40, 593-605.

Liu, Y.H., Romay, F.J., Dick, W.D., Woo, K.S. and Chiruta, M. (2010) A wide-range particle spectrometer for aerosol measurement from $0.01 \mu \mathrm{m}$ to $10 \mu \mathrm{m}$, Aerosol Air Qual. Res., 10, 125-139.

Mok, K.M. and Hoi, K.I. (2005) Effects of meteorological conditions on $\mathrm{PM}_{10}$ concentrations - a study in Macau, Environ. Monit. Assess., 102, 201-223.

Pirjola, J., Lähde, T., Niemi, J.V., Kousa, A., Rönkkö, T., Karjalainen, P., Keskinen, J., Frey, A. and Hillamo, R. (2012) Spatial and temporal characterization of traffic emissions in urban microenvironments with a mobile laboratory, Atmos. Environ., 63, 156-167.

Pitz, M., Schmid, O., Heinrich, J., Birmili, W., Maguhn, J., Zimmermann, R., Wichmann, H.E., Peters, A. and Cyrys, J. (2008) Seasonal and diurnal variation of $\mathrm{PM}_{2.5}$ apparent particle density in urban air in Augsburg, Germany, Environ. Sci. Technol., 42, 5087-5093.

Rolph, G.D. (2013) Real-time Environmental Applications and Display System (READY) website. NOAA Air Resources Laboratory, Silver Spring, MD. (http://ready.arl.noaa.gov).

Yao, X.H., Lau, N.T., Fang, M. and Chan, C.K. (2005) Real-time observation of the transformation of ultrafine atmospheric particle modes, Aerosol Sci. Tech., 39, 831-841.

Yao, X.H., Lau, N.T., Chan, C.K. and Fang, M. (2007) Size distributions and condensation growth of submicron particles in on-road vehicle plumes in Hong Kong, Atmos. Environ., 41, 3328-3338. 